Article

\title{
Suitability of Wooden Shingles for Ventilated Roofs: An Evaluation of Ventilation Efficiency
}

\author{
Günther Kain ${ }^{1,2, *}$, Friedrich Idam ${ }^{2}$, Franz Federspiel ${ }^{3}$, Roman Réh ${ }^{4}$ and L'uboš Krišt'ák ${ }^{4}$ \\ 1 Department for Forest Products Technology and Timber Construction, Salzburg University of Applied \\ Sciences, Markt 136a, 5431 Kuchl, Austria \\ 2 Department for Wood Restoration Technology, Higher Technical College Hallstatt, Lahnstraße 69, \\ 4830 Hallstatt, Austria; idam@gmx.at \\ 3 Freelance Architect, Auweg 11, 4820 Bad Ischl, Austria; franz.federspiel@aon.at \\ 4 Faculty of Wood Sciences and Technology, Technical University in Zvolen, T. G. Masaryka 24, \\ SK-960 01 Zvolen, Slovakia; reh@tuzvo.sk (R.R.); kristak@tuzvo.sk (L'.K.) \\ * Correspondence: gkain.lba@fh-salzburg.ac.at; Tel.: +43-699-819-764-42
}

Received: 25 August 2020; Accepted: 14 September 2020; Published: 17 September 2020

Featured Application: The findings are highly relevant for the roof restoration and maintenance of historic buildings.

\begin{abstract}
Wooden shingles are a traditional roofing material on many culturally important building artifacts. Currently, the roof space of many traditional buildings is used for residential purposes and, consequently, cold roof constructions with ventilation layers are applied. In this study, it is evaluated whether the moisture content of wooden shingles is adversely affected by such constructions, compared with unvented shingle roofs over cold attics and whether a temporary closing of the ventilation gaps at the eaves contributes to a lower wood moisture content. Various sensors were installed in and around a building with wooden shingles on a ventilated roof and temperature, air moisture, and air speed in the ventilation layer were measured throughout a year. The findings show that the air speed in the ventilation layer can be adjusted from 0.06 to $0.25 \mathrm{~m} / \mathrm{s}$ depending on the layout of the eaves. A hygrothermal model was applied to evaluate the effects of different ventilation operation modes and cardinal orientations of the roof on the moisture content of the wooden shingles. The results show that roof ventilation results in a 1\% lower shingle moisture content on average than an unventilated roof over a cold attic. Finally, it is shown that the wood moisture content repeatedly reaches dangerous levels above $25 \%$ throughout a year, which is worse on north-facing roofs and, hence, measures to increase the dry-out are relevant.
\end{abstract}

Keywords: wooden shingles; ventilated roof construction; roof durability; ventilation efficiency; hygrothermal modelling

\section{Introduction}

Until the first quarter of the 20th century, the main roofing material for buildings involved wooden boards and shingles [1] in many parts of the world. On the basis of archeological findings, it can be proven that, in Hallstatt, Upper Austria, already in the Bronze Age (13/12th century before Christ (BC)), wood shingles with a length of 20 to $30 \mathrm{~cm}$ and a width of 10 to $15 \mathrm{~cm}$ were used [2]. The tradition of wooden roof claddings has never completely stopped and, in recent years, along with a renaissance of ecological building materials, wooden shingles are increasingly applied again.

Shingles should be preferably made from slowly grown wood, meaning that there have to be a minimum of four growth rings per $\mathrm{cm}$, because of the higher durability of this wood [3]. The spiral 
grain of the wood is beneficial because rain-wetted shingles twist in the sun and the bottom side dries off more quickly. This results in a low average wood moisture content and adverse conditions for wood-decaying microorganisms [4]. Damage in the roof construction is often the precursor for severe damage in the structure of traditional buildings [5]; consequently, the durability of wooden shingles is a crucial factor in the preservation of building artifacts. It was shown in a study in Norway that the majority of defects in pitched wooden roofs are moisture-related [6]. Wood rots if its equilibrium moisture content is lastingly higher than $20 \%$ because of fungal infection [7]. Wooden roofing only maintains its function sustainably if the wooden shingles dry out regularly below this level [8].

Building elements, such as roofing constructions, are ventilated as this is a simple and effective technical solution to remove undesirable moisture [6]. Already shortly before Christ, the Roman architect Vitruv discussed a ventilated wall construction using the principle of gravity ventilation [9]. Until the 19th century, ventilated roofing constructions were realized using moisture-absorptive, moisture-storing, and at the same time diffusion-open materials like wooden shingles. Moisture accruing in the ventilation layer could be absorbed, stored, transferred, and finally removed without harming the building construction [10]. Partly, the implementation of new materials and constructions such as insulation at the rafter level and roofing underlays in buildings led to moisture problems which were nonexistent before [11].

Due to the efficient ventilation of attics and moisture-buffering effects of hygroscopic materials in historic buildings, the adverse effects of slightly leaking roof claddings are reduced [12]. Traditional roofs are ventilated with cold roof-spaces. The attic room functions as a climatic buffer between the outside heat and cold and the living climate in the parlor areas [12]. Moisture diffusing and streaming (through leakages) from the conditioned spaces into unvented attics in cold climates can cause harmful condensation under cold roof surfaces [13]. Sufficient ventilation of the attic space or thermal insulation of the roof surface can help to prevent the problem, although this depends on the moisture conditions of the introduced air. Insulating roofs at rafter level in these constructions can result in lower temperatures of the roofing and, worse, drying-out [14].

In cold climate regions, roof ventilation can prevent the formation of ice dams due to heat energy which is transported from the conditioned parts of a building to the lower side of the roof via both convection and conduction [15]. This warm air melts the snow on the roof and the melting water freezes at the colder eave of the roof, resulting in ice dams. Ventilated roofs are also applied in hot climates to avoid overheating of the living space, although its effect is minimal in this respect [16]. Moreover, ventilated roof constructions can help to reduce the damage potential of moisture accruing in insulation layers underneath the ventilation layer in cold climates [17].

On the one hand, condensation water can occur inside construction components; on the other hand, it can be formed on the surfaces of construction components when their surface temperature is lower than the dew-point temperature of the surrounding air [18]. Roof surface temperatures can fall below the ambient air temperature due to radiative effects. This leads to condensation of air moisture on cold surfaces. Water and vapour are absorbed by wood, which causes swelling and shrinking when the moisture dries off.

Surface temperatures inside ventilated roofs were shown to be below ambient temperatures for approximately half of the time during spring and autumn in Trondheim, Norway [19]. During the warm season, the moisture input into a construction from the outside air can be significantly larger than that from the inside. Especially problematic is when the air in the ventilation system on the southern roof side is warm and wet and is transferred to the northern roof side, which is cold during spring and autumn. Under these circumstances, intense ventilation was shown to be disadvantageous due to condensation and increasing the moisture content of wooden construction elements [20]. It was shown that, in cold attics, ventilation adds moisture when its relative humidity is higher than $70 \%$ [21]. In north-facing cold attic spaces under the eaves, infiltration of moisture from conditioned spaces, as well as ventilation, can lead to increased moisture levels in the construction; hence, existing construction rules have to be evaluated [22]. Moisture is only removed from the inside air or building 
component by ventilation air when the absolute moisture content of the introduced air is lower than that of the inside air [23].

In this respect, it was shown that the risk of mold growth can be higher in ventilated attics when the climate gets milder and wet due to climate change. Under these circumstances, mechanically ventilated attics are recommended [24]. In ventilated walls, the introduced air can also wet the construction during moist weather conditions [25].

It was shown that transient hygrothermal models are suitable to predict the temperature and moisture conditions in cold roofs [26]. The authors stated that the definition of reliable in- and outdoor climate boundary conditions are especially crucial when creating hygrothermal models, which is also the most important reason for a model's potential deviation from real values.

The reason for this investigation is the assumption that the durability of wooden shingles on ventilated roof (cold roofs) constructions could be shorter than that on constructions with a cold attic space [27]. It is assumed that deficient flow in the ventilation gap and condensation of humid air might be the reason. The research question for this investigation is whether it is recommended to apply wooden shingles on a ventilated roof construction or if their application should be limited to buildings with uninhabited cold attics without ventilation of the roof cladding. The effect of cardinal orientation is also evaluated in this respect. Moreover, it is discussed whether the partial closing of the ventilation gaps results in a lower wood moisture content. This is a relevant question, because historic buildings, which originally had cold attics, are increasingly equipped with roof ventilation in the course of roof refurbishment.

The research question is addressed using the example of a historic building, which originally had no ventilation layer under its wooden shingle roof and which was refurbished applying a ventilation layer under a new wooden shingle roof cladding. Air temperature, humidity, and air speed inand outside the ventilation layer were measured throughout a year. A hygrothermal model of the construction was set up and the measured data were used to validate the model. Finally, the model was used to simulate the effects of varying cardinal orientation of the roof, varying airflow in the ventilation layer, and partial closing of the ventilation layer on the dry-out of the shingles. The results were compared with the performance of the roof without ventilation layer and a cold attic.

\section{Materials and Methods}

The building analysed is located in Weinbach, Salzburg, Austria. Weinbach is situated between Strobl and Bad Ischl at the bottom of a west-east-oriented u-shaped valley at a sea level of approximately $520 \mathrm{~m}$ above sea level. The house was built around 1630 and was used as a mill. The building consists of pure stone masonry with a thickness of 65 and $50 \mathrm{~cm}$ at both levels. The roof is a double-pitch roof with a slope of approximately $38^{\circ}$ (ridge direction north-south) and a small one-sided hip. There is a loggia under the roof on the south façade. The building was bought by a private citizen who plans to use it as a permanent residential building. In a first work phase, the old and damaged roof was refurbished, but renovated using larch wood (Larix decidua Mill.) shingles. The only modification was the implementation of a ventilated roof construction with a ventilation gap on the eave and ridge (eave-ridge distance $470 \mathrm{~cm}$ ). The whole building was neither inhabited nor heated and the roof was not insulated in between rafters during the time of measurement (Figure 1).

Various sensors were positioned in the construction on the western roof side according to Figure 2 and a multi-input data logger was used to store the sensor data. Sensor 1 (bidirectional digital thermoanemometer; air speed $0.08-2 \mathrm{~m} / \mathrm{s}$, resolution $0.001 \mathrm{~m} / \mathrm{s}$; air temperature -20 to $70{ }^{\circ} \mathrm{C}$, resolution $0.1^{\circ} \mathrm{C}$ ) was positioned in the centre of a ventilation gap between two counter battens (width $80 \mathrm{~cm}$ ) in the midst of the building. It was oriented to detect air movement in the ventilation direction. Sensor 2 (another identical thermoanemometer) was positioned at the border of the ventilation gap, next to the counter batten. Sensor 3 (digital sensor for air moisture and temperature; air moisture 5-98\% r.m., precision $\pm 2.0 \%$ r.m.; air temperature -20 to $80^{\circ} \mathrm{C}$, precision $\pm 0.1^{\circ} \mathrm{C}$ ) was positioned in the centre of the ventilation field next to sensor 1 . Identical sensors were used at positions 5 and 6 . Sensor 4 
(temperature sensor $\mathrm{Pt} 100$; temperature -10 to $90^{\circ} \mathrm{C}$, resolution $0.01^{\circ} \mathrm{C}$ ) was applied on the outside wall to control the wall surface temperature. An identical temperature sensor (Sensor 7) was applied on the underside of the shingles at the same position as sensor 1 to control the surface temperature of the shingles. All measurements were stored every $5 \mathrm{~min}$ on an SD-card via the data logger. Measurements were recorded for 365 days, from 24 November 2017 until 24 November 2018, resulting in 35,305 measurements. Sensor 5 was installed on 2 February 2018, resulting in 28,359 measurements.

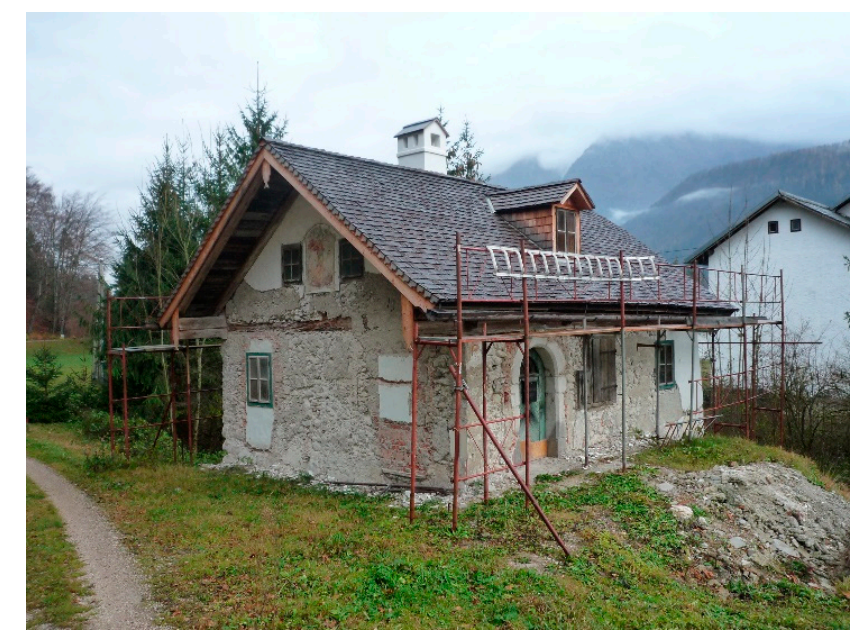

Figure 1. Building object on which measurements were conducted.
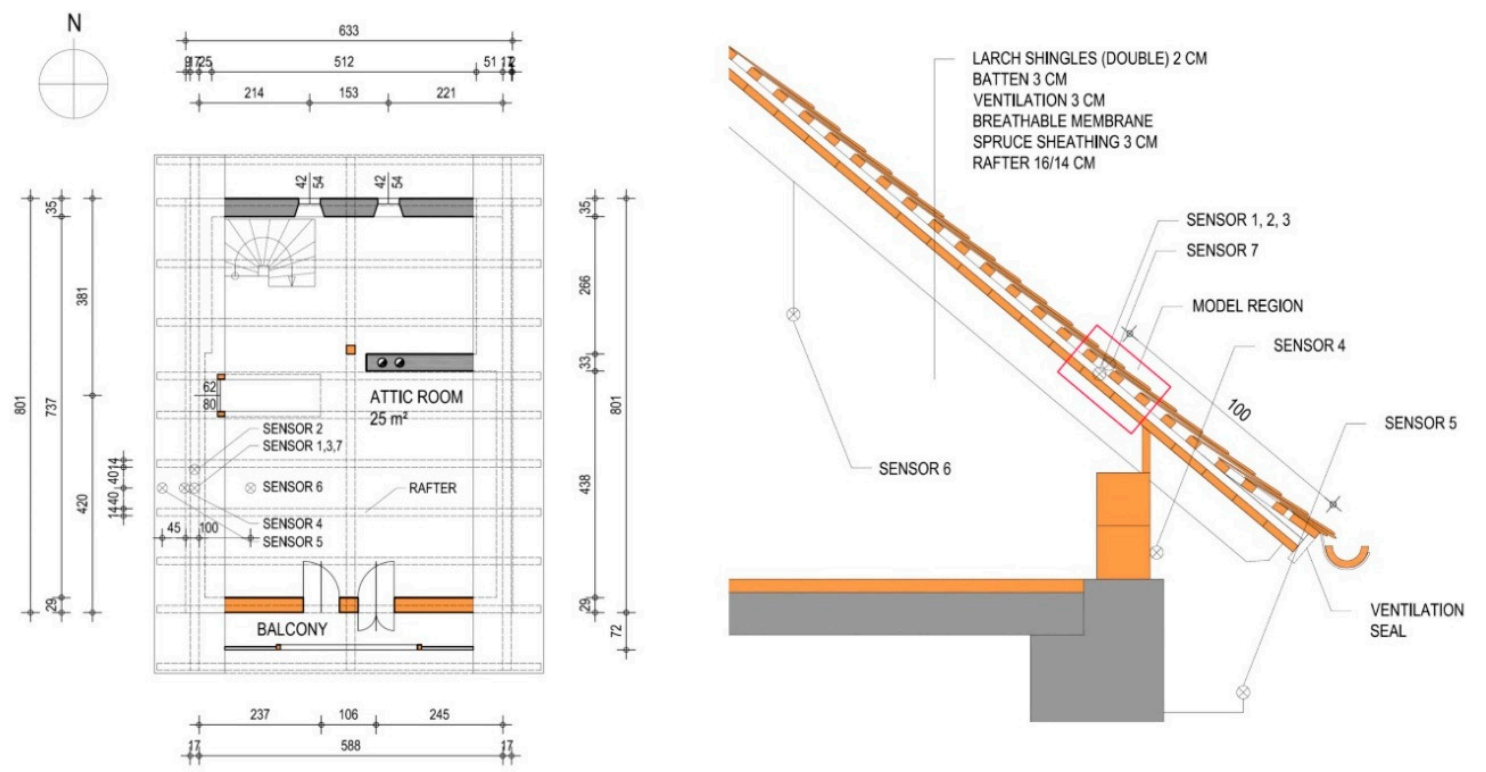

Figure 2. Floor plan and cross-section of the attic room with position of sensors and scope of the finite element (FE) model.

In order to evaluate the effectiveness of the eave-ridge ventilation, the air inlet on the eave was partially closed by a wooden board (as indicated in Figure 2): period 1 (P1) 24 November until 7 December 2017-ventilation layer open at both eaves, period 2 (P2) 7 December until 20 December 2017-ventilation layer closed at the western eave, period 3 (P3) 20 December until 25 January—ventilation open at both eaves, period 4 (P4) 25 January until 1 April—both opposite eaves closed, period 5 (P5) 1 April until 24 November-eaves open.

The measurement variables detected were ambient air temperature (AAT), ambient air moisture (AAM), air temperature in the centre of the ventilation layer (VAT), air moisture in the centre of 
the ventilation layer (VAM), air temperature and air moisture in the attic (AtAT, AtAM), surface temperature of the outside wall (WST), air speed in the ventilation layer in the centre and at the border (VASc and VASb), dew-point temperature of the air in the ventilation layer (VDT), and shingle surface temperature (SST). The partial water vapour pressure of the ambient air (AVP), ventilation air (VVP), and air in the attic (AtVP) was determined using physical relationships.

The resulting measurements were pairwise correlated using Pearson coefficients of correlation. Specific timelines were analysed using linear regression analysis. The graphs covering the time span of a whole year were smoothed using moving averages to the power of 288 . This corresponds to an average of measurements over $24 \mathrm{~h}$.

The dew-point temperature of the air in the ventilation layer was determined according to Equations (1) and (2), and the partial water vapour pressure was determined using well-known relationships. The equilibrium moisture content of wood (EMC), on the basis of the relative moisture content of the surrounding air, was estimated according to Equation (3) [28].

The roof construction was evaluated for 365 days starting 24 November 2017 using the simulation program Delphin 5.8.1 (Bauklimatik Dresden Software $\mathrm{GmbH}$ ) for coupled heat, air, and moisture transport in a two-dimensional consideration. A section with a length of $30 \mathrm{~cm}$, including three roof battens, was considered in the model (Figure 2). The materials larch wood for the shingles with a density of $550 \mathrm{~kg} / \mathrm{m}^{3}$ (absolutely dry) and spruce wood for the battens and the sheathing with a density of $425 \mathrm{~kg} / \mathrm{m}^{3}$ (absolutely dry), and a horizontal air layer with an inclination of $38^{\circ}$ for the ventilation layer were considered. The physical material parameters were used as documented by Bauklimatik Dresden Software GmbH [29] and Sontag et al. [30].

The two shingle layers were simplified by considering two layers of wood with a thickness of $15 \mathrm{~mm}$. The simplification consists of neglecting thin air gaps between shingle layers (a result of wood warping and shrinking) which would ease water input to and moisture dry-out from the lower shingle layer. The moisture ab- and desorption of the sheathing was limited by applying a high water conduction resistance value $\left(5 \times 10^{15} \mathrm{~m} / \mathrm{s}\right)$ on the surface corresponding to the roofing underlay. The temperature of the exterior air (AAT), its relative humidity (AAM), the attic air temperature (AtAT), and its humidity (AtAM) were imposed on the simulation model as boundary conditions using the measured values. A roof pitch of $38^{\circ}$ and western orientation was considered. Hourly values of precipitation, global radiation, and wind velocity were integrated in the model using meteorological data from St. Wolfgang/Austria (measuring point $9 \mathrm{~km}$ from the building site) [31]. In the measuring period, precipitation of $1160 \mathrm{~L} / \mathrm{m}^{2}$ and $1956 \mathrm{~h}$ of sunshine were recorded.

The air stream in the ventilation layer was integrated as a laminar flow. A linear relationship between a pressure gradient between the ventilation layer openings and the air flow was assumed. Pressure differences of $5 \mathrm{~Pa}(0.12 \mathrm{~m} / \mathrm{s}), 3 \mathrm{~Pa}(0.06 \mathrm{~m} / \mathrm{s})$, and $10 \mathrm{~Pa}(0.25 \mathrm{~m} / \mathrm{s})$ between the air in- and outlet of the modeled domain were considered. Longwave radiation across the cavity between the alternate surfaces was considered using an emissivity of 0.9 for both surfaces (shingles and sheathing).

The model domain was discretized using variable discretization (smaller elements at material boundaries) with a minimum element width of $1 \mathrm{~mm}$, which resulted in 1054 elements considered in the model (Figure 2). All results derived from the model are marked with an " $\mathrm{m}$ " below to avoid confusion with measured values.

The temporal course of VAT_m, VAM_m at the specified position according to Figure 2 (equivalent to the sensor position), was modeled as an averaged value of 20 finite elements $(30 \times 30 \mathrm{~mm})$. The model values of SST were determined at the position of the sensor, averaging eight finite elements (length between to roof battens, $75 \mathrm{~mm}$ ). Moreover, the moisture flux (liquid water, vapour diffusion, and convection) was integrated over time at the lower shingle layer's lower surface (Dry-out_w_m). An average of 34 finite elements, corresponding to a length of $30 \mathrm{~cm}$ of the shingle's lower surface, were considered. The dry-out rate (Dry-out rate_w_m) was determined as the derivation of Dry-out_w_m with respect to time. 
Finally, the total moisture mass (liquid, vapour, ice) was determined for the lower and upper shingle halves and referred to the dry mass of the wood (EMC_w_m and EMC_w_u_m). Both values were an average of 136 finite elements $(15 \times 300 \mathrm{~mm})$ each.

First of all, the model values were determined with the air stream in the ventilation layer as measured for all four cardinal orientations of the roof surface. Then, the air speed was set to $0.06 \mathrm{~m} / \mathrm{s}$ (corresponding to the value determined with closed eaves) during the course of the whole year to evaluate the characteristics of a construction with permanently closed eaves (ventilation out of operation and thermal effects on the air speed neglected). Finally, the spruce sheathing in the model was removed, and AtAT and AtAM were considered as boundary conditions at the shingles' lower surface, which represents a shingle roof on a cold attic.

All model values were determined as hourly values, and the measurements were averaged on an hourly basis for comparison with the model. This resulted in 8760 values for each measurement.

The model was validated by comparing real and modeled VAT, SST, VAM, and VVP using a linear regression analysis between real and modeled values in the course of a year (24 November 2017 until 24 November 2018).

$$
\begin{gathered}
p_{s}(\vartheta)=C_{1} * e^{\frac{C_{2} * \vartheta}{C_{3}+\vartheta}}, \\
\vartheta_{\text {dew }}=\frac{C_{3} * \ln \left(\frac{\varphi * p_{s}(\vartheta)}{C_{1}}\right)}{C_{2}-\ln \left(\frac{\varphi * p_{s}(\vartheta)}{C_{1}}\right)},
\end{gathered}
$$

where $p_{s}$ is the saturation vapour pressure for air temperature $\vartheta$ in $\mathrm{Pa}, \vartheta_{\text {dew }}$ is the dew-point temperature in ${ }^{\circ} \mathrm{C}, \varphi$ is the relative air moisture content, $C_{1}$ is a constant (610.5), $C_{2}$ is a constant $(21.875$ for $-50<\vartheta<0{ }^{\circ} \mathrm{C}$ and 17.269 for $\left.0 \leq \vartheta<50{ }^{\circ} \mathrm{C}\right)$, and $C_{3}$ is a constant $\left(265.5\right.$ for $-50<\vartheta<0{ }^{\circ} \mathrm{C}$ and 237.3 for $0 \leq \vartheta<50^{\circ} \mathrm{C}$.

$$
\begin{gathered}
E M C=\frac{1800}{W} *\left(\frac{K * h}{1-K * h}+\frac{\left(K_{1} * K * h+2 * K_{1} * K_{2} * K^{2} * h^{2}\right)}{\left(1+K_{1} * K * h+K_{1} * K_{2} * K^{2} * h^{2}\right)}\right), \\
W=330+0.452 *(T * 1.8+32), \\
K=0.791+0.000463 *(T * 1.8+32)-0.000000844 *(T * 1.8+32)^{2}, \\
K_{1}=6.34+0.000775 *(T * 1.8+32)-0.0000935 *(T * 1.8+32)^{2}, \\
K_{2}=1.09+0.0284 *(T * 1.8+32)-0.0000904 *(T * 1.8+32)^{2},
\end{gathered}
$$

where $E M C$ is the equilibrium moisture content as a percentage, $h$ is the relative humidity expressed in decimal form, and $\mathrm{T}$ is the air temperature in ${ }^{\circ} \mathrm{C}$.

\section{Results and Discussion}

The ambient air temperature (AAT) was measured throughout the year with a minimum of $-15.9^{\circ} \mathrm{C}$ on 28 February 2018 and a maximum of $34.5^{\circ} \mathrm{C}$ on 4 August 2018 (Figure 3). The average temperature during the measuring period accounted for $10.6^{\circ} \mathrm{C}$ (standard deviation (SD) $9.4^{\circ} \mathrm{C}$ ). AAT was well correlated with the air temperature in the ventilation layer (VAT) $(R=0.99)$, the bottom face layer of the wooden shingles (SST) $(R=1.00)$, and the air temperature in the attic (AtAT) $(R=0.95)$ (Tables 1 and 2). 


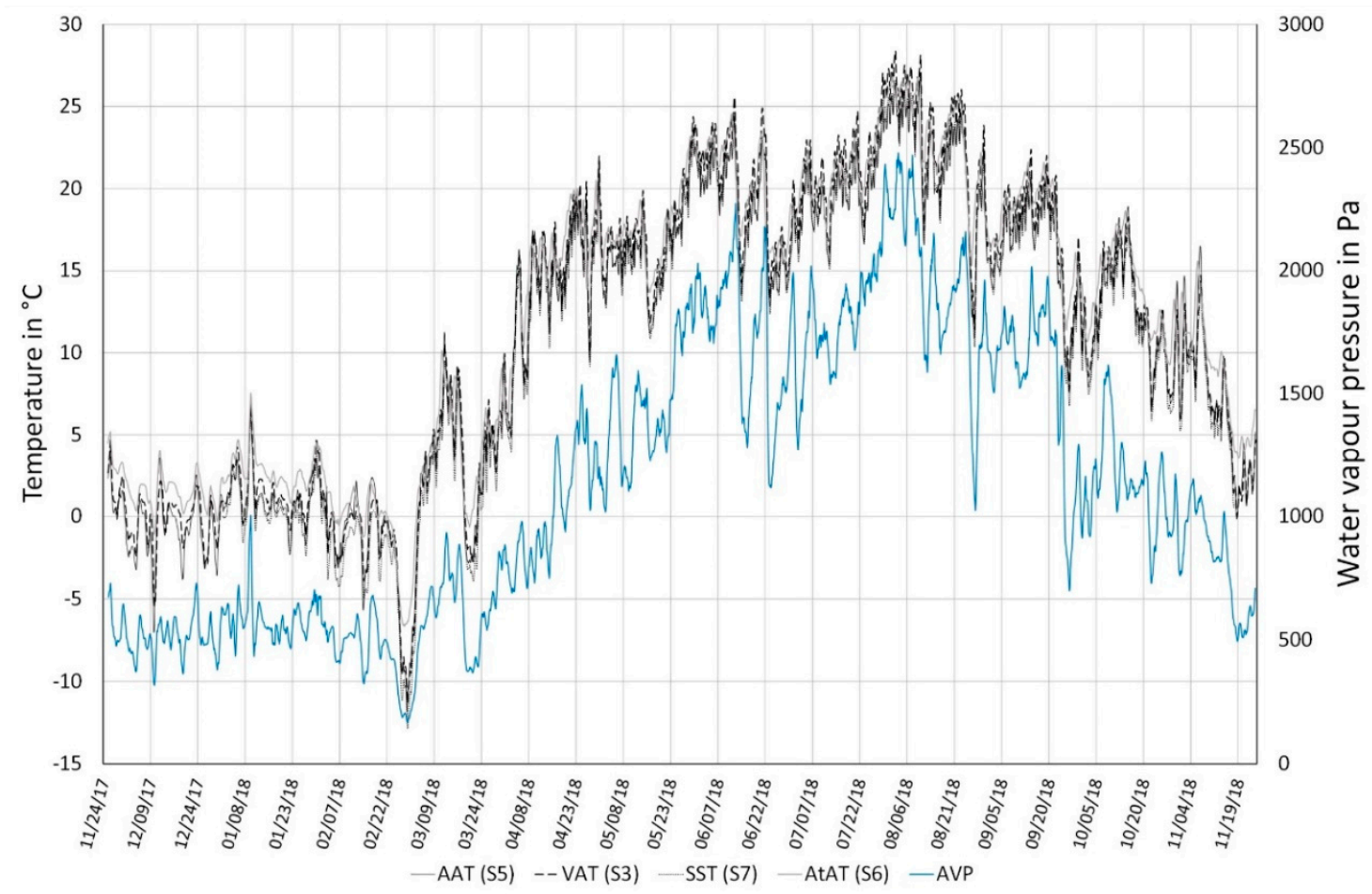

Figure 3. Various temperatures over the total measuring time.

Table 1. Descriptive statistics of measured values and climate data.

\begin{tabular}{cccccc}
\hline Measured Values & & Mean & SD & Min & Max \\
\hline temperature ambient air (AAT) & ${ }^{\circ} \mathrm{C}$ & 10.6 & 9.4 & -15.9 & 34.5 \\
surface temperature wall (WST) & ${ }^{\circ} \mathrm{C}$ & 10.2 & 9.3 & -15.7 & 34.2 \\
air temperature ventilation centre (VATc) & ${ }^{\circ} \mathrm{C}$ & 11.3 & 10.0 & -14.7 & 39.5 \\
air temperature attic (AtAT) & ${ }^{\circ} \mathrm{C}$ & 12.1 & 8.6 & -7.8 & 30.1 \\
dew-point temperature ventilation (VDT) & ${ }^{\circ} \mathrm{C}$ & 6.3 & 7.0 & -17.9 & 21.4 \\
surface temperature shingles bottom (SST) & ${ }^{\circ} \mathrm{C}$ & 10.6 & 9.7 & -16.9 & 35.5 \\
SST-VDT & ${ }^{\circ} \mathrm{C}$ & 2.9 & 3.0 & -6.3 & 19.0 \\
air speed ventilation centre (VASc) & $\mathrm{m} / \mathrm{s}$ & 0.19 & 0.14 & 0.00 & 1.03 \\
air speed ventilation border (VASb) & $\mathrm{m} / \mathrm{s}$ & 0.19 & 0.14 & 0.00 & 1.08 \\
r.h. ambient air (AAM) & $\%$ & 76 & 17 & 22 & 100 \\
r.h. vent. centre (VAM) & $\%$ & 74 & 16 & 22 & 99 \\
r.h. attic (AtAM) & $\%$ & 74 & 13 & 27 & 98 \\
vapour pressure ambient air (AVP) & $\mathrm{Pa}$ & 1140 & 603 & 124 & 4117 \\
vapour pressure ventilation (VVP) & $\mathrm{Pa}$ & 1156 & 605 & 135 & 3351 \\
vapour pressure attic (AtVP) & $\mathrm{Pa}$ & 1208 & 581 & 221 & 2952 \\
global radiation & $\mathrm{W} / \mathrm{m}^{2}$ & 134.0 & 219.5 & 0.0 & 969.4 \\
precipitation & $\mathrm{mm} / \mathrm{m}^{2}$ & 0.1 & 0.6 & 0.0 & 15.0 \\
wind speed & $\mathrm{m} / \mathrm{s}$ & 1.0 & 1.0 & 0.0 & 8.2 \\
wind direction & $\mathrm{degree}$ & 199 & 112 & 0 & 360 \\
\hline
\end{tabular}


Table 2. Paired correlations (Pearson) of investigated measurements.

\begin{tabular}{|c|c|c|c|c|c|c|c|c|c|c|c|c|c|c|c|c|c|c|}
\hline & 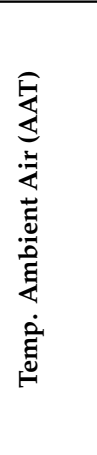 & 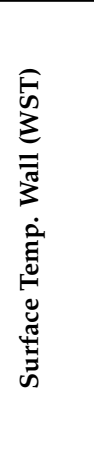 & 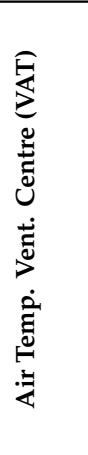 & 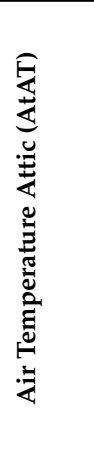 & 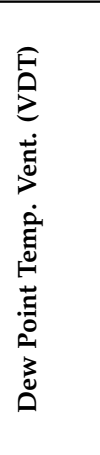 & 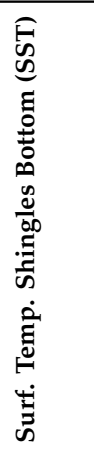 & 点 & 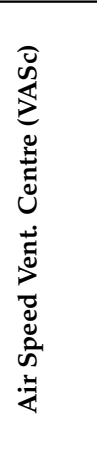 & 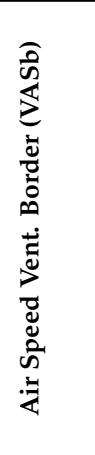 & 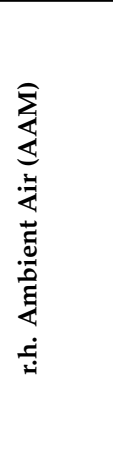 & 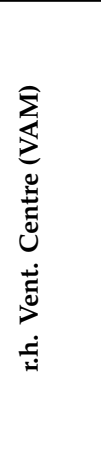 & 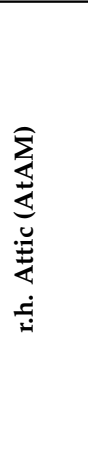 & 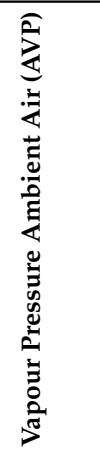 & 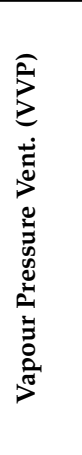 & 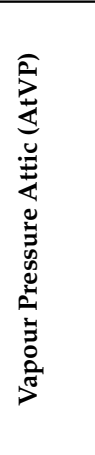 & 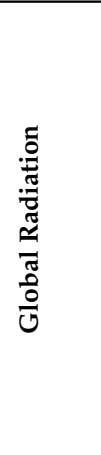 & 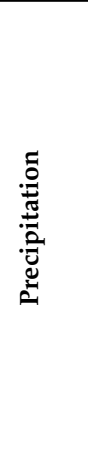 & 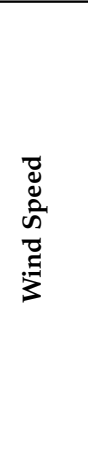 \\
\hline AAT & 1 & & & & & & & & & & & & & & & & & \\
\hline WST & 0.95 & 1 & & & & & & & & & & & & & & & & \\
\hline VAT & $0.99 *$ & 0.95 & 1 & & & & & & & & & & & & & & & \\
\hline AtAT & $0.94 *$ & 0.95 & 0.94 & 1 & & & & & & & & & & & & & & \\
\hline VDT & 0.96 & 0.93 & 0.96 & 0.94 & 1 & & & & & & & & & & & & & \\
\hline SST & $0.99 *$ & 0.95 & 0.99 & 0.95 & 0.96 & 1 & & & & & & & & & & & & \\
\hline SST-VDT & 0.59 & 0.60 & 0.64 & 0.59 & 0.46 & 0.68 & 1 & & & & & & & & & & & \\
\hline VASc & $0.76^{*}$ & 0.76 & 0.75 & $0.82 *$ & 0.73 & $0.76^{*}$ & 0.54 & 1 & & & & & & & & & & \\
\hline VASb & 0.78 & 0.84 & 0.72 & 0.78 & 0.75 & 0.79 & 0.54 & 0.99 & 1 & & & & & & & & & \\
\hline AAM & -0.62 & -0.55 & -0.61 & -0.47 & -0.42 & -0.58 & -0.76 & -0.42 & -0.42 & 1 & & & & & & & & \\
\hline VAM & -0.74 & -0.65 & -0.80 & -0.71 & -0.63 & -0.79 & $-0.91 *$ & -0.63 & -0.63 & $0.84^{*}$ & 1 & & & & & & & \\
\hline AtAM & -0.60 & -0.75 & -0.70 & -0.75 & -0.59 & -0.70 & -0.73 & -0.72 & -0.73 & 0.62 & 0.78 & 1 & & & & & & \\
\hline AVP & $0.89 *$ & 0.87 & 0.89 & 0.91 & 0.95 & 0.92 & 0.46 & 0.70 & 0.72 & -0.31 & -0.58 & -0.58 & 1 & & & & & \\
\hline VVP & 0.94 & 0.90 & 0.95 * & 0.90 & 0.97 * & 0.94 & 0.46 & 0.68 & 0.70 & -0.45 & -0.65 & -0.58 & 0.95 & 1 & & & & \\
\hline AtVP & 0.89 & 0.90 & 0.89 & $0.94 *$ & 0.93 & 0.89 & 0.42 & 0.51 & 0.74 & -0.34 & -0.59 & -0.54 & 0.92 & 0.93 & 1 & & & \\
\hline glo. rad. & 0.52 & 0.47 & 0.53 & 0.37 & 0.42 & 0.42 & 0.28 & 0.30 & 0.30 & $-0.63 *$ & -0.54 & -0.33 & 0.24 & 0.43 & 0.36 & 1 & & \\
\hline precip. & -0.02 & -0.03 & -0.02 & -0.03 & 0.03 & -0.01 & -0.10 & -0.04 & -0.02 & 0.13 & 0.12 & 0.11 & 0.05 & 0.02 & 0.00 & -0.11 & 1 & \\
\hline wind sp. & 0.14 & 0.10 & 0.15 & 0.02 & 0.07 & 0.13 & 0.21 & 0.10 & 0.11 & -0.36 & -0.26 & -0.12 & -0.01 & 0.08 & -0.01 & 0.31 & 0.10 & 1 \\
\hline wind dir. & 0.14 & 0.14 & 0.15 & 0.12 & 0.15 & 0.16 & 0.11 & 0.12 & 0.12 & -0.09 & -0.13 & -0.09 & 0.17 & 0.17 & 0.14 & 0.06 & 0.04 & 0.18 \\
\hline
\end{tabular}


The relative humidity of the ambient air (AAM) was characterized by a minimum of $22 \%$ on 9 April 2018 and a maximum of 100\% several times during the winter of 2017/2018. The average relative air moisture content during the measuring time was $76 \%(\mathrm{SD}=17 \%)$. AAM was correlated with that of the ventilation layer (VAMc) $(R=0.84)$ and that in the attic (AtAM) $(R=0.62)$. Nevertheless, AAM and VAMc were not perfectly correlated as only $71 \%$ of the variation in the VAMc could be explained by AAM (shown by the coefficient of variation $=R^{2}$ ). On average, VAMc was $2 \%$ lower than AAM (Figure 4). Whilst the SD of AAM was 17\%, the SD of AtAM was only $13 \%$ and, in this respect, more languid.

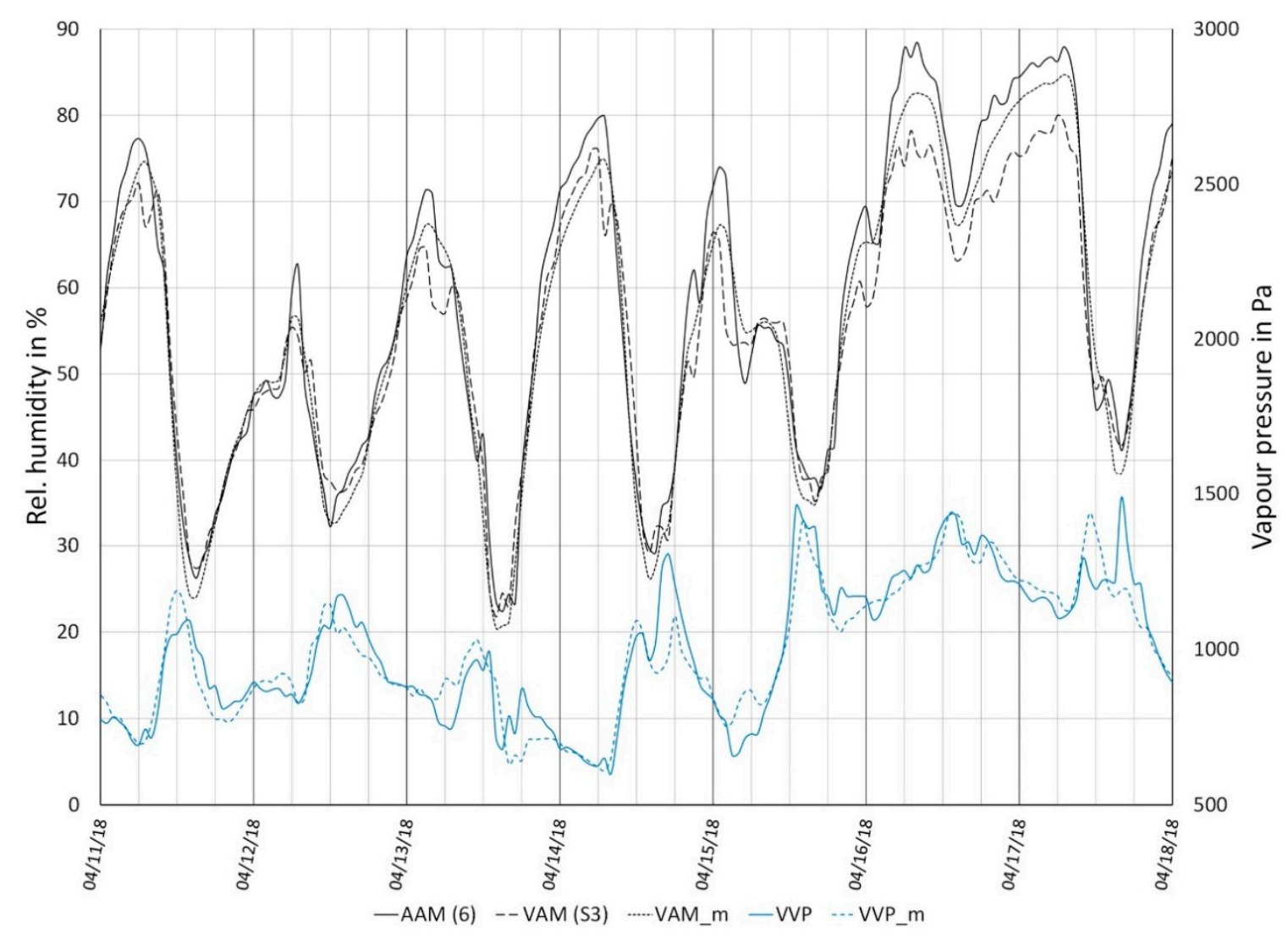

Figure 4. Air moisture content in mid-April 2018.

Focusing on specific time intervals, like that in mid-April 2018 (chosen because of great moisture uptake on the shingles' underside) (Figure 5), the air temperature rose from the morning until the afternoon, which caused the relative humidity to drop and the water vapour pressure to rise (Figure 4). After reaching the top temperature around 4:00 p.m., the relative humidity of the air rose, the vapour pressure dropped, and the shingle lower surface was wetted during the night. This could be observed throughout the year (the dry-out rate was negative $45 \%$ of the year). The $24 \mathrm{~h}$ balance of Dry-out rate_w_m was predominantly positive (i.e. drying) from the end of November 2017 until mid-April 2018 and varied the rest of the year. Whenever the slope of the cumulated dry-out curve in Figure 6 is low, the shingles' lower surface was partly wetted by the inflowing air. Periods with a low slope of the dry-out timeline indicate a low balance of the dry-out. The vapour pressure (AVP) was positively correlated $(R=0.91)$ with the air temperature (AAT). 


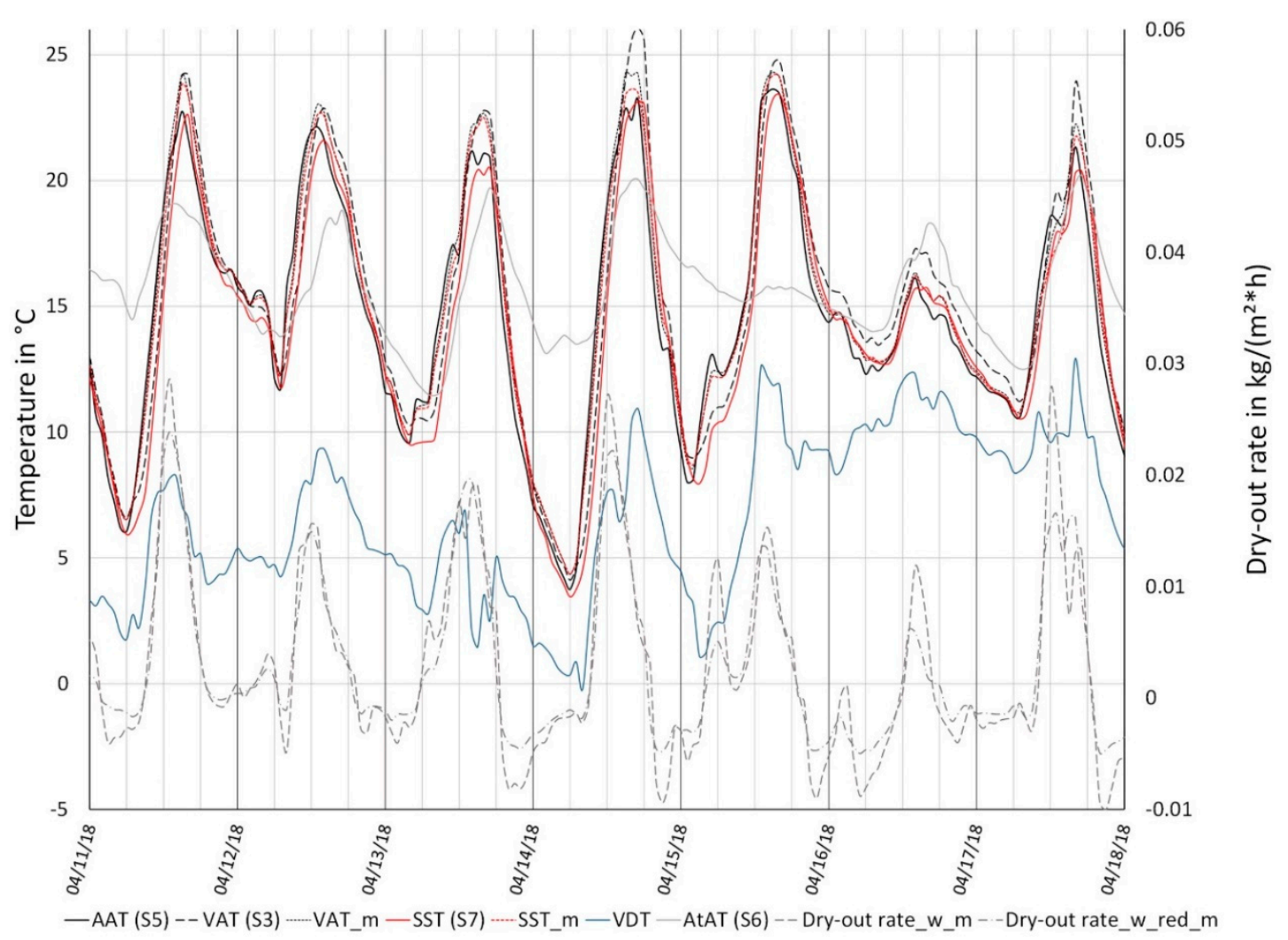

Figure 5. Various temperatures and dry-out rates of the lower shingle layer in spring 2018.

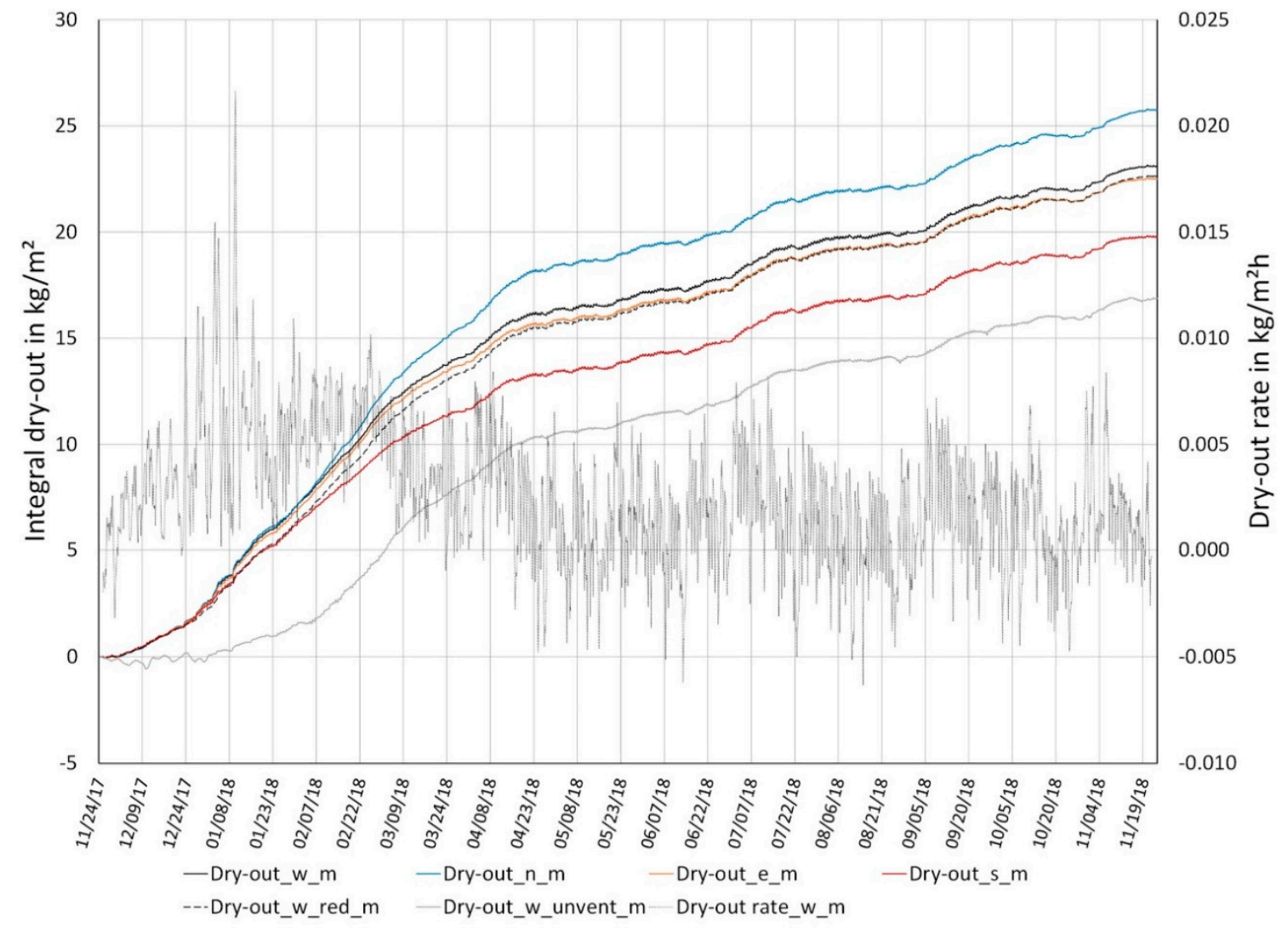

Figure 6. Integral dry-out for normal and reduced ventilation and dry-out rate. 
The surface temperature on the shingles' bottom surface fell below the dew-point temperature of the inflowing air $6.3 \%$ of the measuring time, which was also mentioned to an even larger extent by Gullbrekken et al. [19]. This corresponds to $180 \mathrm{~h}$ of potential condensation. The time when the shingles' lower side temperature was lower than the dew-point temperature was concentrated $99 \%$ in one half of the year (1 November to 1 May). During this time, $12 \%$ of the time condensation conditions were detected. How much the dew point temperature was undercut (SST-VDT) was strongly indirectly correlated $(R=-0.91)$ with the VAM. In the beginning of April 2018 in the morning hours, SST fell strongest below VDT throughout the whole measuring time (Figure 7). The shingles did not take up a lot of moisture in this time (shown by predominantly positive values of Dry-out rate_w_m), because the vapour pressure (AVP, VVP) was low during that time, meaning that the air carried a low amount of water (Figure 3). Consequently, it was not the condensation of moisture that caused the most moisture uptake on the shingles' lower surface, but moist inflowing air in the warm season (shown in Figure 6 during time intervals with a low slope of the cumulated dry-out curve).

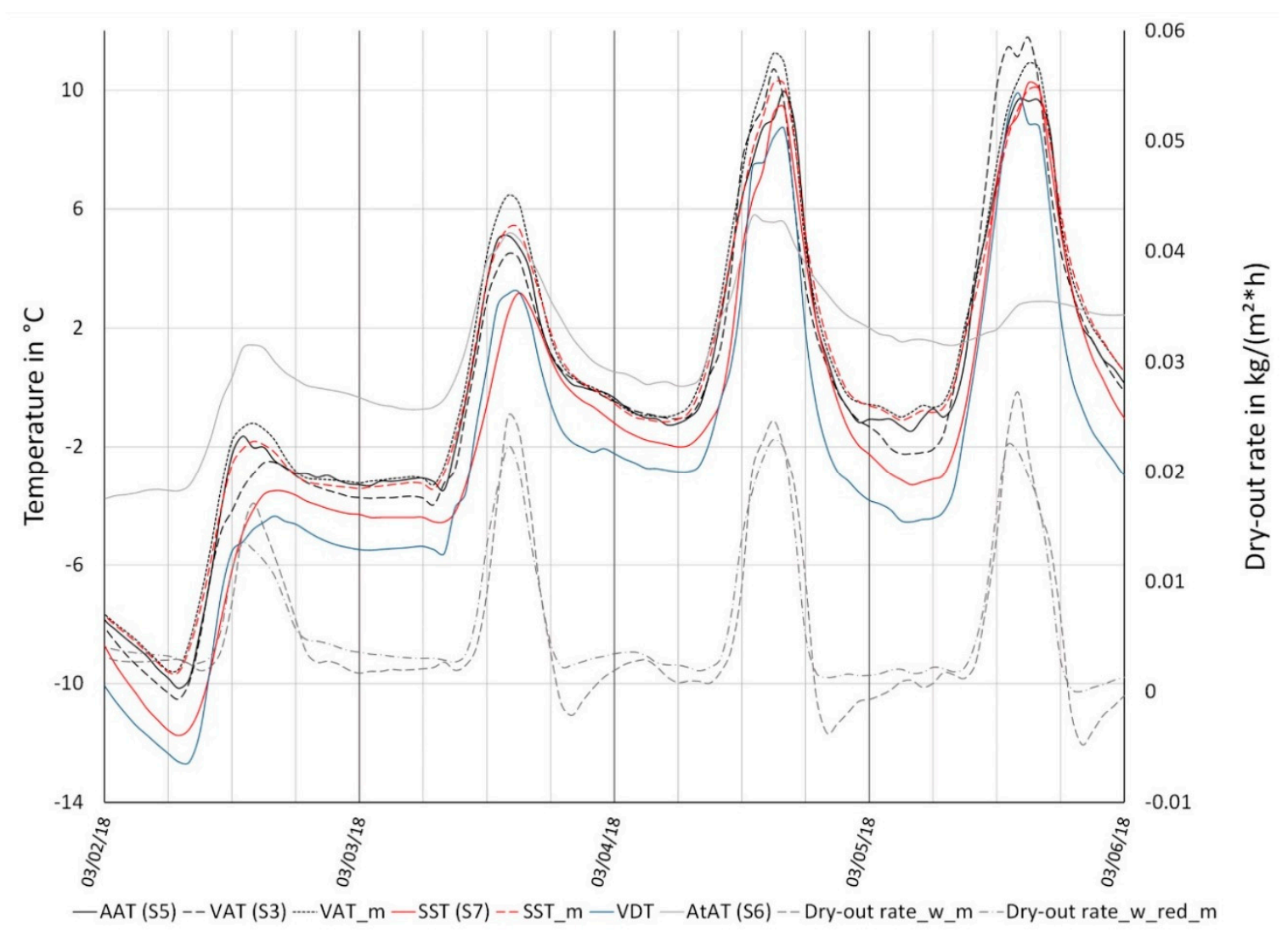

Figure 7. Various temperatures and dry-out rates of the lower shingle layer in the beginning of March 2018.

The surface temperature of the shingles on the side of the ventilation space (SST) was well correlated with the air temperature in the ventilation layer (VAT) $(R=0.99)$ and was on average $0.7^{\circ} \mathrm{C}$ lower than VAT. This was probably caused by long-wave radiation of the shingles to the sky [18], heat flow from the inside to the ventilation air (AtAT was on average $0.8^{\circ} \mathrm{C}$ higher than VAT), and snow, partly lying on the shingles in the beginning of 2018. Snowfall was recorded on 40 days from the start of the measurements until the end of March 2018 and was a reason for the stronger deviations of SST from VAT during the winter months (Figure 3).

The air speed in the ventilation layer in the centre (VASc) showed a minimum value of $0 \mathrm{~m} / \mathrm{s}$ and a maximum of $1.03 \mathrm{~m} / \mathrm{s}$ and was well correlated $(R=0.99)$ with the air speed at the border (VASb). The average air speed in the ventilation centre was $0.19 \mathrm{~m} / \mathrm{s}$. The variability was high with a SD 
of $0.14 \mathrm{~m} / \mathrm{s}$. During the first measuring period P1 (ventilation open), the average of the air speed accounted for $0.12 \mathrm{~m} / \mathrm{s}$; during P2 (western eave closed), the average of the air speed accounted for $0.06 \mathrm{~m} / \mathrm{s}$; during P3 (ventilation open), the average of the air speed accounted for $0.12 \mathrm{~m} / \mathrm{s}$; during P4 (both opposite eaves closed), the average of the air speed accounted for $0.06 \mathrm{~m} / \mathrm{s}$; during P5 (ventilation open), the average of the air speed accounted for $0.25 \mathrm{~m} / \mathrm{s}$ (Figure 8). The air speed at the border of the ventilation field was on average insignificantly lower (on average $0.003 \mathrm{~m} / \mathrm{s}$ ) than in the center. It could be shown that, by closing one eave (P2), the average air speed in the ventilation layer could be reduced by $50 \%$. VASc was positively correlated with AAT $(R=0.76)$ and AtAT $(0.82)$ meaning that higher air temperatures resulted in a higher air flow in the ventilation layer. In the summer half-year, the average air speed in the ventilation layer was twice as high as in the winter when the eaves were open, which supports this conclusion.

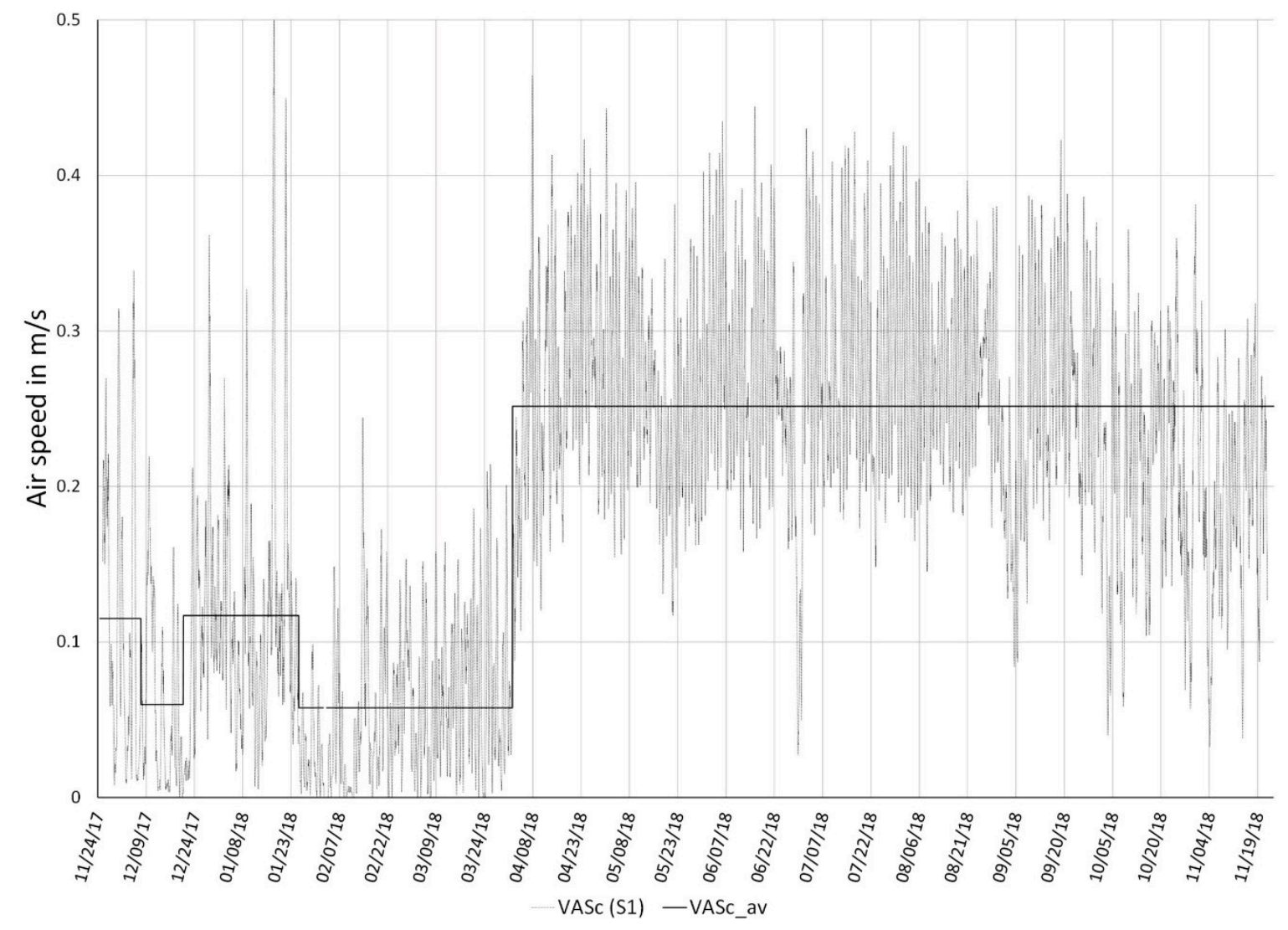

Figure 8. Air speed in the ventilation layer over the total measuring time.

Comparing P2 with the western eave open and P4 with both opposite eaves closed, the air speed was the same, but the average of AAT was $12.2^{\circ} \mathrm{C}$ higher in $\mathrm{P} 4$ than in $\mathrm{P} 2$, while the wind conditions were comparable (average wind speed P2 $1.2 \mathrm{~m} / \mathrm{s}, \mathrm{P} 40.9 \mathrm{~m} / \mathrm{s}$; average wind direction P2 $205^{\circ}, \mathrm{P} 4190^{\circ}$ ) and there was a positive correlation of AAT and VASc. This suggests that there was additional air-flow hindrance when both eaves were closed. Considering a ventilation gap between two battens $\left(0.8 \times 0.03 \mathrm{~m}^{2}\right)$, the air flow ranged between $5.2 \mathrm{~m}^{3} / \mathrm{s}$ and $21.6 \mathrm{~m}^{3} / \mathrm{s}$.

The quality of the hygrothermal model was assessed by comparing the values of the in situ measurements of VAT, VAM, VVP, and SST with the modelled correspondent by calculating linear regression functions between measured and modelled values of the same quantity (Table 3). The coefficient of correlation $\left(R^{2}\right)$ between VAT and VAT_model was 0.99 , and VAT was on average $0.4^{\circ} \mathrm{C}$ underestimated by the model. $R^{2}$ between SST and SST_model accounted for 0.99 and overestimated the real value on average by $0.1{ }^{\circ} \mathrm{C}$ (Figure 7). The interdependence of VAM and VAM_model was 
characterized by an $R^{2}$ of 0.90 , whereby the model overestimated VAM by $3 \%$ (Figure 4 ). The coefficients of determination of the VAT and SST models are high. The fit of the VAM model was, considering the high variability of the air moisture [26], adequate. The vapour pressure, which is a characteristic for the water in the air, was modelled, and VVP_m deviated on average $10 \mathrm{~Pa}$ or $0.9 \%$ from VVP $\left(R^{2}=\right.$ 0.96). This suggests that the general trend in VVP was correctly traced by VVP_m.

Table 3. Descriptive statistics of modelled values and correlations with measured values.

\begin{tabular}{ccccccc}
\hline Measured or Modelled Value & & Mean & SD & Min & Max & $\boldsymbol{R}^{2}$ \\
\hline VAT & ${ }^{\circ} \mathrm{C}$ & 11.3 & 10.0 & -14.7 & 39.5 & \\
VAT_m & ${ }^{\circ} \mathrm{C}$ & 10.9 & 9.5 & -15.1 & 36.1 & 0.99 \\
VAM & $\%$ & 74 & 16 & 22 & 99 & \\
VAM_m & $\%$ & 77 & 17 & 20 & 99 & 0.90 \\
SST & ${ }^{\circ} \mathrm{C}$ & 10.6 & 9.7 & -16.9 & 35.5 & \\
SST_m & ${ }^{\circ} \mathrm{C}$ & 10.7 & 9.5 & -15.2 & 36.3 & 0.99 \\
VVP & $\mathrm{Pa}$ & 1156 & 605 & 135 & 3351 & \\
VVP_m & $\mathrm{Pa}$ & 1146 & 570 & 158 & 2900 & 0.96 \\
EMC_w_m & $\%$ & 23 & 13 & 10 & 54 & \\
EMC_w_red_m & $\%$ & 24 & 15 & 10 & 57 & \\
EMC_w_u_m & $\%$ & 34 & 22 & 9 & 85 & \\
EMC_w_u_red_m & $\%$ & 34 & 23 & 9 & 86 & \\
EMC_n_mod & $\%$ & 26 & 15 & 11 & 57 & \\
EMC_n_red_m & $\%$ & 27 & 18 & 10 & 64 & \\
EMC_e_m & $\%$ & 22 & 13 & 10 & 53 & \\
EMC_e_red_m & $\%$ & 23 & 14 & 10 & 55 & \\
EMC_s_m & $\%$ & 20 & 10 & 10 & 46 & \\
EMC_s_red_m & $\%$ & 20 & 10 & 9 & 46 & \\
EMC_w_unvent_m & $\%$ & 26 & 18 & 10 & 65 & \\
EMC_w_opt_m & $\%$ & 23 & 13 & 10 & 54 & \\
EMC & $\%$ & 16 & 4 & 10 & 54 & \\
\hline
\end{tabular}

The modelled moisture content of the shingles' upper layer (EMC_w_u_m) was on average 34\% $(\mathrm{SD}=22 \%)$, while that of the lower layer (EMC_w_m) was on average $23 \%(\mathrm{SD}=13 \%)$. The EMC of this study was not measured directly, but derived from the model [30]. A lower bound for the modelled data was EMC, determined according to Mitchel [28], representing the EMC without rain influence, which was in good agreement with the modelled values whenever the level of precipitation was low during summer 2018 (Figure 9). Literature values report an average moisture content of unsheltered weathered wood in Sweden, mounted with an angle of $45^{\circ}$, of $46 \%$ for pine sapwood and $25 \%$ for pine heartwood [32]. EMC_w_u_m in this study varied between the two values. The source cited supports the modelled results of the current study, but uncertainty is present; therefore, the results for EMC should be rather interpreted as basic trends, and they were primarily used to evaluate differences in the operation mode of the ventilation in this study.

The MC of the upper shingle layer was predominantly affected by precipitation, causing the peaks in Figure 9. EMC_w_m was higher than EMC with an average of 16\% (SD $=4 \%$ ) (the moisture content of the shingles if there was no precipitation). Hence, the lower shingle layer was also significantly influenced by precipitation throughout the year, being stronger at the beginning (the peaks of precipitation are delayed in the EMC of the shingles in Figure 9). 


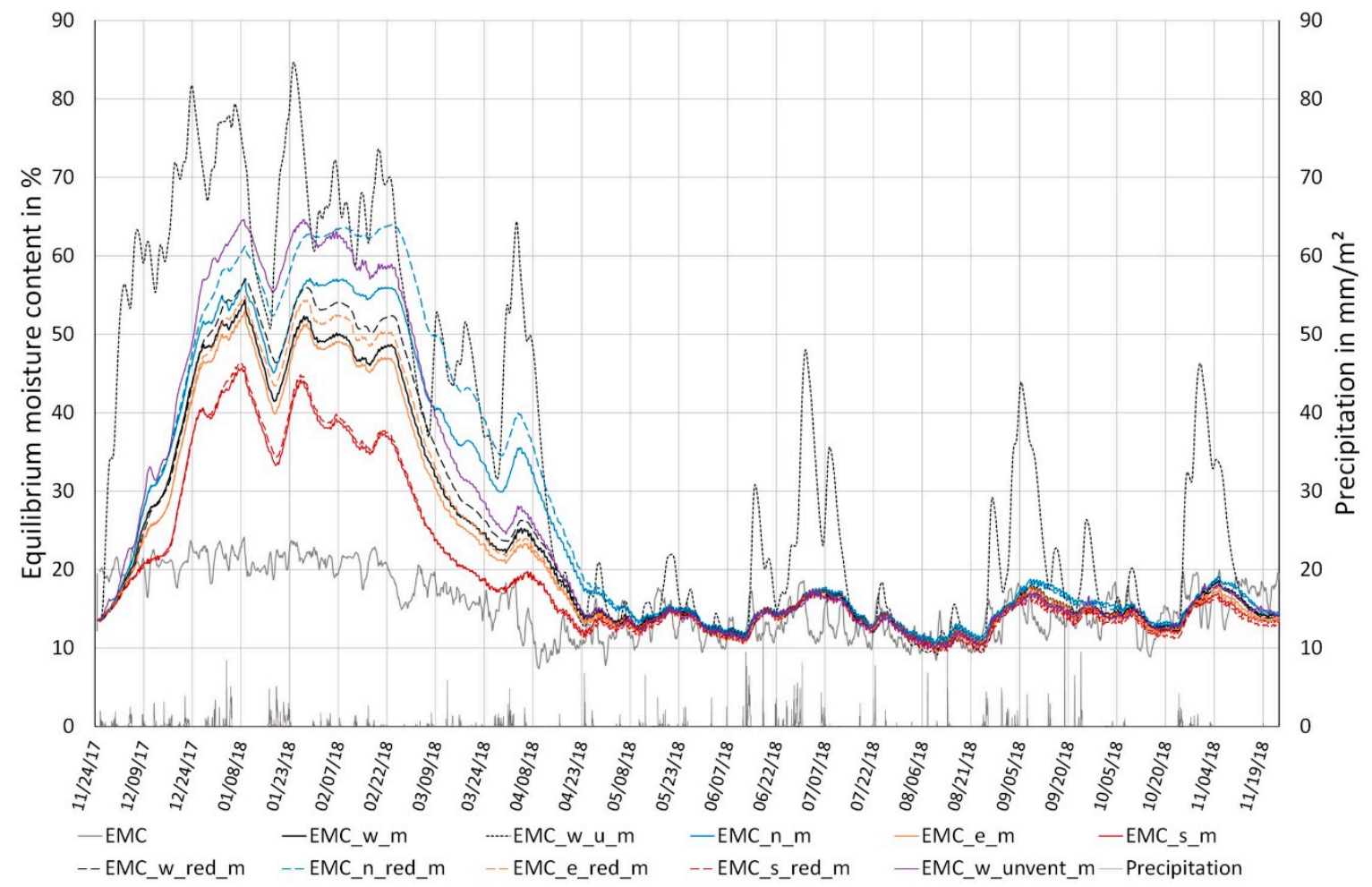

Figure 9. Moisture content of the lower and upper shingle layer.

The EMC of the lower shingle layer was on average around 37\% (SD $=14 \%$ ) from the end of November 2017 until mid-April 2018 and then dropped to an average of 14\% (SD $=2 \%)$ for the rest of the year. The risk for decay is high if the EMC is lastingly higher than $25 \%$ and the temperature stays above $5{ }^{\circ} \mathrm{C}$ [33]. From the end of November until mid-April, the model showed an EMC of more than $25 \%$ for both shingle layers, and the temperature was above $5{ }^{\circ} \mathrm{C} 20 \%$ of the time. For the rest of the year, the upper shingle layer's EMC bounced between 10\% and 70\%. The lower shingles' EMC varied between $10 \%$ and $20 \%$. The analysis shows that, during the warm season, the upper shingles' EMC was repeatedly in a rot danger region. Consequently, strategies to lower the EMC (by improved dry-out) are advantageous, even if the improvement is low (Figure 9). According to the model applied, the lower shingles were not at risk of decay from midst of April until end of November. This temporal course of wood moisture is in good agreement with findings of Isaksson and Thelandersson [33], albeit with lower precipitation; hence, a lower average moisture level was measured in this study.

The lower shingle layer took up moisture from the streaming air in the ventilation layer $45 \%$ of the time (Figure 6). Whilst the mechanism of wetting and drying the lower shingle surface varied during the day (Figure 7), there were times, especially during the warm season, where the shingles were more severely wetted by the inflowing air. Focusing on the balance of moisture take-up and dry-out in Figure 6 throughout a year, more moisture was removed by ventilation than carried in. This is a strong argument for the ventilation of shingle layers and contradicts the findings of Künzel [20] stating that ventilation is not desirable a significant part of the year. If the eaves were permanently closed and the VASc was $0.06 \mathrm{~m} / \mathrm{s}$ (thermal effects on the air speed neglected), the average MC of the lower shingle layer would be $24 \%$ (SD = 15\%), $1 \%$ higher than with the open ventilation layer (Figure 9). EMC_w_u_m was not significantly affected by closing the ventilation gaps (Table 3).

The roof construction was also evaluated without roof ventilation applying the attic climate (AtAT, AtAM) as a boundary condition below the shingles. The EMC of the lower shingle layer would be on average $26 \%(\mathrm{~S}=18 \%), 3 \%$ higher than with the vented one and $2 \%$ higher than that with reduced ventilation. The moisture dry-out would be $17 \mathrm{~kg} / \mathrm{m}^{2}$ throughout the measuring period, $6 \mathrm{~kg} / \mathrm{m}^{2}$ 
less than with ventilation layer. The disadvantageous effects of reduced ventilation or an unvented construction were more pronounced during the winter months.

Considering that ventilation of the shingle roofing is desirable when the lower shingle surface does not take up moisture from the ventilation air and that the air speed in the ventilation layer can be influenced by coverage on the eaves, technical solutions for steered ventilation are worthy of consideration [21]. This would require flaps at the eaves which are steered depending on the evaluation of air moisture, shingle temperature, amount of solar irradiation, and general weather conditions (e.g., snow on the roof). An estimation for the effects of this approach was conducted by closing the eaves in the model whenever it showed a negative moving average of $6 \mathrm{~h}$ dry-out rate (i.e. the air speed was set to 0.06 or $0.25 \mathrm{~m} / \mathrm{s}$, and the thermal effects were neglected). On average, the EMC of the lower shingle layer (EMC_w_opt_m) was $0.3 \%$ lower compared with EMC_w_m. In the current situation, this effect is minimal because it is superimposed by the effects of wetting due to rain. Nevertheless, this could be an interesting optimization of ventilated constructions which are not subjected to direct rain, such as ventilated facades. In this context, bio-actuators to steer the ventilation gaps, as proposed by Rüggeberg and Burgert [34] or Holstov et al. [35], could find a meaningful future application.

If the attic is inhabited and heated, moisture diffusion and convection might interfere with the mechanisms studied in this project. The construction would be equipped with a vapour retarder under the insulation, but the moisture flow through leakages may be significant [36]. Presumably, the moisture transport from the inside to the outside would be minimal because of vapour barriers applied on the inner side of the roof construction. The heat flow from the inside might slightly raise surface temperatures in the ventilation layer, which would diminish the condensation problems. This effect may also be minimal, because constructions tend to be very well insulated. Nevertheless, these multifactorial processes should be studied in further research.

In the current study, a roof of western orientation was studied. The unmodified roof construction was evaluated for the other cardinal directions as well, changing the boundary conditions in the software. In Figure 9 and Table 3, one can see that the modelled EMC of the lower shingle layer was highest on a north-facing roof with an average of $26 \%(\mathrm{SD}=15 \%)$ and lowest on a south-facing roof with an average of $20 \%$ (SD $=10 \%$ ). The differences were most significant during the cold time of the year (end of November until mid-April). This findings are in good agreement with a study focusing on the fungal decay of wood in different microclimates showing that all studied wood species have a higher risk of decay in shaded areas [37]. Focusing on the dry-out rate, it was highest with a north-facing orientation $\left(26 \mathrm{~kg} / \mathrm{m}^{2}\right)$ and lowest with a south-facing orientation $\left(20 \mathrm{~kg} / \mathrm{m}^{2}\right)$. As both roof orientations were flown through with the same air in the model, it follows that the south-facing roof's lower shingle layer was dried up to the top more efficiently, because there was a higher drying potential of the sun. Evaluating the surface temperature on the shingles' exterior surface, the average temperature accounted for $13.3^{\circ} \mathrm{C}(\mathrm{SD}=11.9)$ east, $14.1^{\circ} \mathrm{C}(\mathrm{SD}=12.5)$ south, $12.6^{\circ} \mathrm{C}(\mathrm{SD}=12.0)$ west, and $11.6^{\circ} \mathrm{C}(\mathrm{SD}=10.8)$ north. Hence, it can be concluded that efficient ventilation is more important on roofs with less sun exposition. In Figure 6, one can see that the dry-out of the shingles' lower surface increased from the south, followed by east, west, and north, and this was indirectly proportional to the radiation of sunlight, confirming this finding. This was also seen when comparing the average moisture content of a ventilated roof and one with closed eaves (Table 3). Whilst the average EMC was unchanged for the south-facing roof, the EMC of a roof with reduced ventilation on the northern side was on average $1 \%$ higher. The modelled effects of cardinal orientation on the wood moisture of shingles need to be verified in further in situ measurements in subsequent investigations. Furthermore, it will be necessary to evaluate other effects such as cracks as a result of wood shrinkage on the shingle surface, which could cause significant local changes of moisture conditions after several years of exposure [38], and such as ascending forces when air is heated up in sun-exposed ventilation layers. 


\section{Conclusions}

This study suggests that, when applying a shingle roof cladding with two layers of wooden shingles on a ventilated pitched cold roof, the following aspects should be considered:

(a) The major source of wood moisture in the studied clime (alpine climate) is precipitation. Whereas the upper shingles' moisture content is directly affected by the rain (rain peaks correspond to peaks in EMC_w_u_m in Figure 9), the lower shingles' EMC is much less affected due to the shield of the upper shingles. The dry-out of the upper (outer) and lower shingle layer is predominantly affected by the ambient climatic conditions. In this respect, measures to enhance the shingles' dry-out to the outer side are very effective. This is, for example, achieved with wooden shingles with spiral grain twist when they dry [4].

(b) The application of ventilation layers under wooden shingle roofs (i.e. cold roof constructions) are preferred compared to unvented (warm roof) constructions because the average wood moisture content is lower in this case. Reducing the air speed in the ventilation layer by blocking the air inlet at the eaves results in a higher EMC and is not recommended.

(c) The location of the building and the cardinal point of the roof orientation are of great importance. The current investigation focused on the alpine climate of central Europe and a roof of western orientation (with low solar irradiation). On a roof facing north or which is overshadowed, the solar irradiation and dry-out of the lower shingle layer to the top are lower, and the effectiveness of the ventilation layer underneath is of greater importance.

(d) Effective ventilation depends on control of ambient air temperature, shingle surface temperature, and relative humidity in- and outside of the construction, and it was shown that, in the current study, the lower side of the shingles took up moisture from the ventilation air in a daily cycle $45 \%$ of the time. This effect was strongest between mid-April and the end of October (high water vapour pressures).

(e) It is recommended to ventilate shingle roofs, but a slightly lower average wood moisture content could be realized if the ventilation layer is closed when the inflowing air wets the shingle lower surface (due to condensation or moisture absorption). The effectiveness of this measure is low $(-0.3 \%$ of EMC on average) and would hardly justify the effort for an opening and closing mechanism.

(f) The EMC of the shingles (upper and lower layer) rises to a high level (40-80\% according to the model applied) during the winter time and temporarily during the summer. Effective ventilation helps to quickly dry out the shingles in the lower layer in the spring time. Moreover, wooden shingles as a roof cladding in the alpine climate repeatedly show a moisture content which favours the growth of microorganisms. Roof claddings are a borderland for wood use, which requires an integrative application of strategies to lower the shingles' moisture content.

The interactions with building physical processes occurring when the attic space is conditioned need to be studied in further research. Likewise, the wood moisture content in this study was estimated using a numerical model and has to be verified in an experimental study. Finally, the study has strong implications for the preservation and renovation of traditional wooden roof claddings in the preservation of cultural heritage buildings. If wooden shingles are considered for the application on traditional buildings, ventilated cold roofs are recommended.

Author Contributions: Conceptualization, G.K. and F.I.; formal analysis, G.K.; funding acquisition, F.F., R.R., and L'.K.; investigation, G.K. and F.F.; methodology, G.K.; project administration, R.R. and L'.K.; software, G.K.; validation, G.K.; writing-original draft, G.K. and F.I.; writing—review and editing, G.K., F.I., F.F., R.R., and L'.K. All authors have read and agreed to the published version of the manuscript.

Funding: This research was supported by the Slovak Research and Development Agency under contracts no. APVV-18-0378, APVV-19-0269, and VEGA 1/0717/19.

Conflicts of Interest: The authors declare no conflict of interest. 


\section{References}

1. Kern, A.; Kowarik, K.; Rausch, A.; Reschreiter, H. Salz-Reich, 7000 Jahre Hallstatt; Veröffentlichung der Prähistorischen Abteilung; Naturhistorisches Museum: Wien, Austria, 2008.

2. Morton, F. Salzkammergut; Verlag des Musealvereins Hallstatt: Hallstatt, Austria, 1984.

3. Policinska, A.; Marzena, S. Wooden shingles in modern construction industry. For. Wood Technol. 2013, 84, 170-175.

4. Stadler, F. Steirische Almsiedlung im Dachsteingebiet. In Bauen-Wohnen-Gestalten: Festschrift für Oskar Moser zum 70. Geburtstag; Eberhart, V., Jontes, V., Katschnig-Fasch, E., Eds.; Publikation des Universalmuseums Joanneum Schloss Trautenfels: Trautenfels, Austria, 1984.

5. Irbe, I.; Karadelev, M.; Andersone, I.; Andersons, B. Biodeterioration of external wooden structures of the Latvian cultural heritage. J. Cult. Herit. 2012, 13, 79-84. [CrossRef]

6. Gullbrekken, L.; Kvande, T.; Jelle, B.; Time, B. Norwegian pitched roof defects. Buildings 2016, 6, 24. [CrossRef]

7. Berdahl, P.; Akbari, H.; Levinson, R.; Miller, W.A. Weathering of roofing materials-An overview. Constr. Build. Mater. 2008, 22, 423-433. [CrossRef]

8. De Groot, R.; Nesenson, P. Performance of preservative-treated wood shingles and shakes. In Proceedings of the 11th Conference on Roofing Technology, Gaithersburg, MD, USA, 21-22 September 1995; pp. $20-22$.

9. Vitruvius, P.; Reber, F. De Architectura libri decem: Zehn Bücher über Architektur; Marix Verlag: Wiesbaden, Germany, 2018.

10. Arendt, C. Fehlerquellen bei der Klimaregulierung historischer Gebäude. Restauratorenblätter 1995, 15, 71-84. [CrossRef]

11. Brennan, T.; Cummings, J.; Lstiburek, J. Unplanned airflows \& moisture problems. ASHRAE J. 2002, 44, $44-49$.

12. Radinger, G. Learning form vernacular buildings-Traditional rural architecture in Austria and its adaption on climatic conditions. In Proceedings of the 4th WTA International PhD Symposium, Delft, UT, USA, 13-16 September 2017.

13. Rudd, A. Field performance of unvented cathedralized (UC) attics in the USA. J. Build. Phys. 2005, 29, 145-169. [CrossRef]

14. Wood, C.; Brocklebank, I.; Pickles, D. Energy efficiency and historic buildings. In Application of Part L of the Building Regulations to Historic and Traditionally Constructed Buildings; English Heritage: London, UK, 2017.

15. Blom, P. Venting of attics and pitched, insulated roofs. J. Build. Phys. 2001, 25, 32-50. [CrossRef]

16. Lstiburek, J. Understanding attic ventilation. ASHRAE J. 2006, 48, 36-45.

17. Moghaddaszadeh Ahrab, M.A.; Akbari, H. Hygrothermal behaviour of flat cool and standard roofs on residential and commercial buildings in North America. Build. Environ. 2013, 60,1-11. [CrossRef]

18. Vogt, D. Tauwasserschäden bei zweischaligen Kaltdach-Konstruktionen-Die Alternative: Schaumglas-Warmdach-Konstruktionen. Restor. Build. Monum. 2001, 7, 580-583. [CrossRef]

19. Gullbrekken, L.; Kvande, T.; Time, B. Ventilated wooden roofs: Influence of local weather conditions-Measurements. Energy Procedia 2017, 132, 777-782. [CrossRef]

20. Künzel, H. Belüften von Wand- und Dachkonstruktionen-Notwendig oder schädlich? Bausubstanz Z. Nachhalt. Bau. Bauw. Denkmalpfl. 2013, 4, 38-43.

21. Hagentoft, C.-E.; Kalagasidis, A.S. Drying potential of cold attic using natural and controlled ventilation in different Swedish climates. Procedia Eng. 2016, 146, 2-7. [CrossRef]

22. Jensen, N.F.; Bjarløv, S.P.; Johnston, J.; Pold, C.F.; Hansen, M.H.; Peuhkuri, R.H. Hygrothermal assessment of north-facing, cold attic spaces under the eaves with varying structural roof scenarios. J. Build. Phys. 2019, 44, 3-36. [CrossRef]

23. U.S. Environmental Protection Agency. Moisture Control Guidance for Building Design, Construction and Maintenance; U.S. Environmental Protection Agency: Washington, DC, USA, 2013.

24. Nik, V.M.; Sasic Kalagasidis, A.; Kjellström, E. Assessment of hygrothermal performance and mould growth risk in ventilated attics in respect to possible climate changes in Sweden. Build. Environ. 2012, 55, 96-109. [CrossRef]

25. Tariku, F.; Iffa, E. Empirical model for cavity ventilation and hygrothermal performance assessment of wood frame wall systems: Experimental study. Build. Environ. 2019, 157, 112-126. [CrossRef] 
26. Mundt-Petersen, S.O.; Harderup, L.-E. Predicting hygrothermal performance in cold roofs using a 1D transient heat and moisture calculation tool. Build. Environ. 2015, 90, 215-231. [CrossRef]

27. Bundesdenkmalamt. Standards der Baudenkmalpflege; Paul Gerin GmbH: Wolkersdorf, Austria, 2014.

28. Mitchel, P. Calculating the equilibrium moisture content for wood based on humidity measurements. Bioresources 2018, 13, 171-175. [CrossRef]

29. Bauklimatik Dresden Software GmbH. Delphin-Programm und Modelldokumentation. Available online: www.bauklimatik-dresden.de/delphin/documentation.php (accessed on 18 April 2020).

30. Sontag, L.; Nicolai, A.; Vogelsang, S. Validierung der Solverimplementierung des hygrothermischen Simulationsprogramms Delphin; Technical Report; Technische Universität Dresden: Dresden, Germany, 2013.

31. Zentralanstalt für Meterologie und Geodynamik. Klimamonitoring. Available online: https://www.zamg.ac. at (accessed on 18 April 2020).

32. Blom, Å.; Bergström, M. Untreated Scots pine (Pinus sylvestris) and Norway spruce (Picea abies) wood-panels exposed out of ground contact in Sweden for two years. Holz Roh Werkst. 2006, 64, 53-61. [CrossRef]

33. Isaksson, T.; Thelandersson, S. Experimental investigation on the effect of detail design on wood moisture content in outdoor above ground applications. Build. Environ. 2013, 59, 239-249. [CrossRef]

34. Rüggeberg, M.; Burgert, I. Bio-inspired wooden actuators for large scale applications. PLoS ONE 2015, 10, e0120718. [CrossRef] [PubMed]

35. Holstov, A.; Bridgens, B.; Farmer, G. Hygromorphic materials for sustainable responsive architecture. Constr. Build. Mater. 2015, 98, 570-582. [CrossRef]

36. Zheng, R.; Janssens, A.; Carmeliet, J.; Bogaerts, W.; Hens, H. Performances of highly insulated compact zinc roofs under a humid-moderate climate-Part I: Hygrothermal behaviour. J. Build. Phys. 2010, 34, 178-191. [CrossRef]

37. Brischke, C.; Rapp, A.O. Influence of wood moisture content and wood temperature on fungal decay in the field: Observations in different micro-climates. Wood Sci. Technol. 2008, 42, 663-677. [CrossRef]

38. Niklewski, J.; Brischke, C.; Frühwald Hansson, E.; Meyer-Veltrup, L. Moisture behavior of weathered wood surfaces during cyclic wetting: Measurements and modelling. Wood Sci. Technol. 2018, 52, 1431-1450. [CrossRef]

(C) 2020 by the authors. Licensee MDPI, Basel, Switzerland. This article is an open access article distributed under the terms and conditions of the Creative Commons Attribution (CC BY) license (http://creativecommons.org/licenses/by/4.0/). 